\title{
DisasterAWARE - A GLOBAL ALERTING PLATFORM FOR FLOOD EVENTS
}

\author{
P. Sharma ${ }^{1 *}$, J. Wang 2 , M. Zhang ${ }^{1}$, C. Woods ${ }^{3}$, B. Kar $^{4}$, D. Bausch ${ }^{5}$, Z. Chen ${ }^{1}$, K. Tiampo ${ }^{3}$, M. Glasscoe ${ }^{6}$, G. Schumann ${ }^{7}$, M. $^{2}$ \\ Pierce $^{2}$, R. Eguchi ${ }^{8}$ \\ ${ }^{1}$ School of computing and engineering, University of Missouri, Kansas City, Kansas City, MO 64110, USA - (pswzg, mz9kk, \\ chenzhiq)@umsystem.edu \\ ${ }^{2}$ Cyberinfrastructure Integration Research Center, Indiana University, Bloomington, IN 47405, USA - (wang208, marpierc)@iu.edu \\ ${ }^{3}$ Geological Sciences, University of Colorado, Boulder, CO 80309, USA - (clwo4142, Kristy.Tiampo)@ colorado.edu \\ ${ }^{4}$ Oak Ridge National Laboratory, Oak Ridge, TN 37831, USA - karb@ornl.gov \\ ${ }^{5}$ Pacific Disaster Center, Kihei, HI 96753, USA - dbausch@pdc.org \\ ${ }^{6}$ Jet Propulsion Laboratory, California Institute of Technology, Pasadena, CA 91109, USA - margaret.t.glasscoe@jpl.nasa.gov \\ ${ }^{7}$ Dartmouth Flood Observatory, Hanover, NH 03755, USA - gjpschumann@ gmail.com \\ ${ }^{8}$ ImageCat Inc., Long Beach, CA 90802, USA - rte@imagecatinc.com
}

\section{Commission IV}

KEY WORDS: Flood forecasting, Alerting, Synthetic Aperture Radar, Model of Models, Impact Assessment, Geospatial Data Fusion

\begin{abstract}
:
The rising number of flooding events combined with increased urbanization is contributing to significant economic losses due to damages to structures and infrastructures. From a risk reduction and resilience perspective, it is not only essential to forecast flood risk and potential impacts, but also to disseminate the information to stakeholders on the ground for rapid implementation of mitigation and response measures. This paper provides (i) an introduction to DisasterAWARE $\AA$, a global alerting system, that is used to disseminate flood risk information to stakeholders across the globe, and (ii) a discussion of the models implemented using earth observation data (Synthetic Aperture Radar and optical imagery) for near real-time assessment of flood severity and potential flood impacts to infrastructures. While the models are still in their nascent stage, a case study implementation of the models for the 2020 flooding event in Africa is presented to showcase the model integration with DisasterAWARE®.
\end{abstract}

\section{INTRODUCTION}

Despite the widespread focus on disaster resilience in recent years, resilience is a widely used concept with a long history (Holling, 1973; Engle et al., 1996). Over the years, significant research has been conducted to define, describe and assess resilience. Whatever the definition, resilience is a dynamic condition that changes across space and time and focuses on increasing the ability and capacity of a system (be a community or an infrastructure) to return to a new normal after disasters by absorbing, responding, adapting, and reorganizing into a fully functioning system with minimal loss and within a short period (McCubbin, 2001; Bruneau et al., 2003; Klein et al., 2003; Paton \& Johnston, 2006; Cutter et al., 2008). Resilience is the product of socio-economic, cultural, and political variables, but is also influenced by science and technological innovations (Tinch 1998; Mileti 1999; Rose 2004). Being a multidimensional concept, its operationalization requires achieving four properties robustness, resourcefulness, rapidity, and redundancy (Bruneau et al., 2003; Renschler et al., 2010).

Risk assessment and risk communication are two pre-cursors to increasing resilience as they ensure dissemination of situational awareness information to stakeholders to aid with preparedness, mitigation, and response activities (UN/ISDR, 2005; Donovan et al., 2019). Even the Sendai Framework has identified the need for successful risk communication along with the use of geospatial technologies and remotely sensed data to aid with resilience and risk reduction activities (UN 2015). The goal of risk communication is to provide adequate information about an impending hazard to aid communities in taking preparatory actions to reduce adverse impacts of the event (Reynolds \& Seeger, 2005; Gladwin et al., 2007; Krimsky, 2007). Though conventional alert and warning devices (e.g. outdoor sirens, radio/weather radio, digital and residential phones) are still used, the growth in technology has enabled message dissemination via cell towers, commercial mobile service providers, and social media and social networking sites (e.g. Twitter, Face book, Flickr) (Palen et al., 2009; FEMA, 2012). For instance, the USGS PAGER (Prompt Assessment of Global Earthquakes for Response) is a communication platform that delivers rapid assessment and impact analysis for earthquakes worldwide (Earle et al., 2009).

While a global earthquake alerting system is in place, no such system currently exists for flood events. Flooding is one of the most frequent hydro-meteorological hazards that causes significant losses i.e. about $\$ 10$ billion (USD) in financial losses annually (CRED, 2020). In 2004, experts from the United Nations University estimated that flood events impact over half a billion people every year worldwide and might impact two billion people by 2050 (University, 2004). To that end, although, significant efforts such as improving flood risk mapping (Dutta, Herath, \& Musiake, 2006), flood risk and impact assessments (Winsemius, Van Beek, Jongman, Ward, \& Bouwman, 2013) flood forecasting (Jain et al., 2018; Olesen,

* Corresponding author 
Löwe, \& Arnbjerg-Nielsen, 2017) are underway, we need a global alerting system capable of forecasting flood events and disseminating flood impacts in near real-time. This paper discusses the DisasterAWARE® platform, which is a global alerting system. In the next section, a discussion of the platform along with the integrated model components implemented for flood forecasting and impact assessment are presented.

\section{METHODOLOGY}

\subsection{Disaster Aware}

DisasterAWARE® is a cloud based software available as service technology and maintained by the Pacific Disaster Centre (PDC). DisasterAWARE® uses both Open Source and proprietary software to provide multi-hazard warning and situational awareness information for decision support through mobile apps and web-based platforms. Both local public and government entities can use licensed version of these platforms. End users can easily receive the alert from public site or the freely available Disaster Alert app for an iphone and android, and so far, $2 \mathrm{M}$ apps have been downloaded.

End users can select the severity level (Warning, Watch, Advisory and Information) for each hazard within the global, country or regional reach. These alerts are based on a combination of official sources, PDC detection automated algorithms and manually entered hazards alerts and, associated situational awareness. DisasterAware uses SmartAlert to determine the alerting area for each hazard based on magnitude, location and type. For example, a tsunami may be local, regional or pacific wide based on location, magnitude and depth criteria used by official sources. Similarly, for earthquake, it applies attenuation functions to determine the impacted areas based on local geology, magnitude and depth to enhance alerting. Subsequently earthquake severity levels are adjusted once the USGS PAGER product is available.

The Global Disaster Alerting Coordination System (GDACS) is a joint initiative between the United Nations Office for the Coordination of Humanitarian Affairs and the European Commission. The system is similar to DisasterAWARE® as it disseminates disaster related information for international relief efforts. However, DisasterAWARE® has more hazards and more platform types available that increase user flexibility. Furthermore, DisasterAWARE® alerting is based on a combination of official sources, detection algorithms and manually entered hazards and alerts. The alert data is also combined with risk and exposure layers to generate situational awareness products for response. Essentially, DisasterAWARE provides uique and efficient tools for multi-hazard warning such that user is presented with a commom operating picture supporting their entire operation. However, the the current system does not have the automated alerting capability for flood events. The models discussed herein are now being integrated with DisasterAWARE® to generate flood alert at a global scale.

\subsection{Flood Modelling Components}

An integrated modeling approach is implemented to forecast and assess risk and flood impacts in near real-time across the globe. The three components of the model are (i) Model of Models (MoM) to integrate outputs from hydrologic models and imagery for flood forecasting and risk assessment, (ii) flood extent and depth modeling using synthetic aperture radar (SAR) imagery at a granular level for high severity floods identified in step 1 and for integration with MoM, and (iii) infrastructure impact assessment using high-resolution optical imagery and geospatial data sets. The following sections provide a brief overview of each modeling component followed by the results of each model for a 2020 flood event.

2.2.1 Model of Models (MoM) to integrate hydrologic models for flood forecasting and risk assessment: Although several hydrologic models are available for flood forecasting (Jain et al. 2018), in this study, GloFAS (Global Flood Awareness System) and GFMS (Global Flood Monitoring System) models were used. These two flood models are globally operational with a wide range of users (Emerton et al., 2016). GFMS is functional for a quasi-global latitude range $\left(50^{\circ} \mathrm{N}\right.$ $50^{\circ} \mathrm{S}$ ) that generates outputs at high spatial (about $12 \mathrm{~km}$ ) and temporal ( 3 hours) resolutions, and is developed by the National Aeronautics and Space Administration (NASA) and the University of Maryland (Wu et al., 2014). From several GFMS products, flood depth above the threshold is used in our model, which is obtained from the University of Maryland (http://flood_umd.edu/) in binary raster format.

The GloFAS system, independent of administrative and political boundaries, is a global hydrological forecast and monitoring system jointly developed by the European Commission and the European Centre for Medium-Range Weather Forecasts (ECMWF) (Alfieri et al., 2013). The system couples state-ofthe-art weather forecasts with a hydrologic model to provide downstream countries with information on upstream river conditions. From the GloFAS products, the ensemble predictions of return period events $(2,5$, and 20 years), alert level (Medium, High, Severe), and peak forecast (in days) within world basins are used in our model.

Assessment and analysis of risk associated with flood events for at-risk communities must reflect the dynamic nature of the risk because of the changing nature of a hazard, exposure, and vulnerability (Viner et al., 2020), and such information is crucial for reducing flood impacts (Dutta et al., 2006). For this purpose, the GFMS and GloFAS model outputs were integrated at watershed boundaries developed by the World Resources Institute (WRI). The 16,385 static watershed boundaries from WRI provide Riverine Flood Risk (RFR) score and Coastal Flood Risk (CFR) score calculated annually. The RFR score for watershed boundaries is computed based on inundation caused by a river overflow, exposure (population in a flood zone), and vulnerability (flooded population and existing level of flood protection) (Hofste et al., 2019). Figure 1 depicts the steps implemented to integrate the flood models and watershed risk to get the MoM outputs.

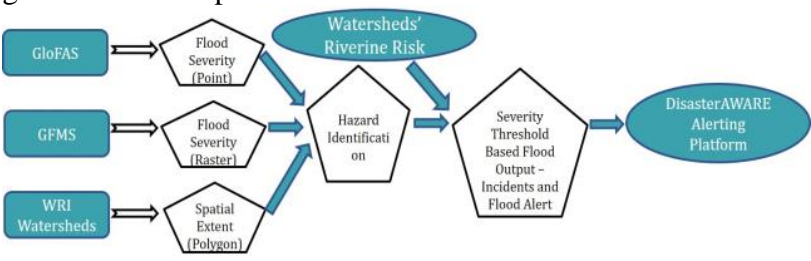

Figure 1. Flowchart for flood model integration (MoM)

For the MoM approach, using GFMS product (flood depth above the threshold), the following parameters were derived: watershed area and percentage of the area impacted by a flood, depth above baseline (mean and max), and duration of a flood (cumulative hours) for the watershed every 24 hours. Within each watershed, GloFAS products were used to determine the ensemble predictions of streamflow above the threshold for 2,5 , 
and 20-year return period flood events, alert level based on severity, and the number of days until the peak forecast arrival every 3-hours. Finally, a weighting scheme was implemented to determine the hazard score using each model at the same watershed (Table 1, refer to Kar et al. 2020 for further discussion about weighting scheme). Flood severity at each watershed was computed using a Cumulative Distribution Function (CDF) such that the total dynamic hazard score from both models are fitted with a logarithmic value of scaled RFR score as mean and unit standard deviation. Flood severity score is subsequently used to geo-target SAR imagery processing for granular flood extent and depth estimation as well as optical imagery processing for impact assessment. Flood severity is also used for alerting by DisasterAWARE® based on the following classification - "Warning" (severity >=75\%), "Watch" $(50 \leq$ Severity < 75), "Advisory" $(25 \leq$ Severity $<50)$ and "Information" $(0 \leq$ Severity $<25)$.

\begin{tabular}{|c|c|}
\hline Product Description & Initial Weighting \\
\hline $\begin{array}{l}\text { The total area of watershed } \\
\text { impacted by the flood }\end{array}$ & $\begin{array}{l}1 \mathrm{pt} \text { for every } 1000 \mathrm{sqkm} \text {, } \\
\mathrm{Max}=10\end{array}$ \\
\hline $\begin{array}{l}\text { Percentage of watershed area } \\
\text { impacted from flood }\end{array}$ & $\begin{array}{l}10 \mathrm{pt} \text { for } 100 \% \operatorname{Max}=10 \\
(\mathrm{eg} .66 \%=6.6)\end{array}$ \\
\hline $\begin{array}{l}\text { The mean depth of flood above } \\
\text { the threshold in a watershed in } \\
\mathrm{mm}\end{array}$ & $\begin{array}{l}1 \mathrm{pt} \text { for every } 10 \mathrm{~mm} \text {, Max } \\
=10(\text { eg. } 56 \mathrm{~mm}=5.6)\end{array}$ \\
\hline $\begin{array}{l}\text { Max depth of flood above } \\
\text { threshold in a watershed in mm }\end{array}$ & $\begin{array}{l}1 \mathrm{pt} \text { for every } 100 \mathrm{~mm} \text {, Max } \\
=10(\mathrm{eg} .890 \mathrm{~mm}=8.9)\end{array}$ \\
\hline $\begin{array}{l}\text { Number of } 3 \text {-hr intervals a } \\
\text { specific area has been flooded } \\
\text { (at least } 100 \text { square km overlap } \\
\text { in each interval) }\end{array}$ & $\begin{array}{l}\text { Continuous days of at least } \\
100 \text { sqkm overlap, } 1 \text { per } \\
\text { day, Max }=10 \text { (eg. } 66 \mathrm{hrs}= \\
2.75)\end{array}$ \\
\hline $\begin{array}{l}\text { EPS greater than threshold } \\
\text { exceedance for } 2,5 \text { and } 20 \text { year } \\
\text { return period flood event }(\%)\end{array}$ & $\begin{array}{l}10 \mathrm{pt} \text { for } 100 \% \text { Max }=10 \\
(\mathrm{eg} .66 \%=6.6)\end{array}$ \\
\hline $\begin{array}{l}\text { Alert Level } 12 \text { and } 3 \text { with } 3 \\
\text { greatest value }\end{array}$ & $\begin{array}{l}1,2 \text { and } 3=3,7 \text { and } 10 \\
\text { respectively }\end{array}$ \\
\hline $\begin{array}{l}\text { Number of days until the peak } \\
\text { forecast arrives at an } \\
\text { observation point }\end{array}$ & $\begin{array}{l}\text { Weight in days where } 1 \\
=10,2=9, \ldots 10 \text { or greater }= \\
1\end{array}$ \\
\hline
\end{tabular}

Table.1 Weighting scheme for hazard score

2.2.2 Flood extent and depth modeling using SAR imagery at a granular level: SAR offers the unique advantage of all-weather data collection at Earth's surface, which is advantageous for flood mapping due to the likelihood of heavy cloud cover during heavy rainfall events. In this study, imagery from the European Space Agency's (ESA) Sentinel-1A/B satellite (C-band SAR) that has a 6-12 day repeat period over large areas was used, which enabled using high temporal and spatial resolution imagery over large regions ideal for flood mapping. This data is publicly available from NASA's Alaska Satellite Facility Distributed Active Archive Center (ASF DAAC) in both single look complex (SLC) and high-resolution ground range detected (GRD) data (Copernicus, 2015).
A threshold method was employed to map inundated regions based on the low backscatter coefficient of the SAR data. Using the method of Cao et al. (2019), SAR data with the appropriate power transform will follow a bimodal Gaussian distribution. We exploit this characteristic to automatically determine a threshold for the image to classify water and non-water regions. The image is split into tiles due to different sections of the SAR scene behaving differently because of a wide swath (Cao et al. 2019). Each tile is analyzed separately to determine its unique threshold. Each tile is further split into an array of $s \mathrm{x} s$ pixels to determine the sets of pixels within this tile that have a bimodal Gaussian distribution using the maximum normalized betweenclass variance (BCV) (Demirkaya et al. 2004, Cao et al. 2019). Based on simulations, it was determined that a maximum value of BCV greater than 0.65 can be assumed to be bimodal. The value of $s$ is varied to maximize the number of bimodal sets of pixels within each tile. For each set of pixels, an automatic threshold is selected using either the mode of the distribution or the local minimum separating the peaks in the bimodal distribution. The mean of the thresholds for each set of $s \times s$ pixels is used as the threshold for the entire tile. This process is repeated for each tile in the image to generate a binary output displaying the classified water regions. Because this method also classifies water which is more permanent rather than a result of flooding events, a set of images is used to remove the common classifications among all images, assuming sufficient temporal coverage. This method can be applied to both VV (vertical-vertical) and $\mathrm{VH}$ (vertical-horizontal) polarizations to improve accuracy as well as to for coherence images to further refine the method. This method of tiling also has the potential to be used in machine learning algorithms to detect changes among tiles for flood detection.

\subsubsection{Infrastructure impact assessment using high-} resolution optical imagery and geospatial datasets: Using the flood extent output from both MoM and SAR imagery, we implemented a deep learning approach using optical imagery to extract impacted building footprints. Although, few building footprints datasets are available such as open-source Microsoft Building footprints, which is limited to Canada, USA, and Uganda/Tanzania (Bing Maps Team, 2018) and, Spacenet (126k building footprints from Atlanta) (Etten, Lindenbaum, \& Bacastow, 2019), data availability for a global approach is still lacking. So, a model was developed to obtain the building footprints from readily available satellite images. The first step within this component is a Mask R-CNN model which efficiently detects objects in an image while simultaneously generating a high-quality segmentation mask for each instance (He, Gkioxari, Dollár, \& Girshick, 2017). This Mask R-CNN model is then trained over the xBD dataset for building detection and boundary delineation. This $\mathrm{xBD}$ dataset uses imagery from Maxar's Open Data Program, which delivers native $30 \mathrm{~cm}$ resolution satellite imagery with Atmospheric Compensation. Also, this dataset is the largest building damage assessment dataset so far with 850,000 building annotations consisting damage scale category (No Damage, Minor Damage, Major Damage, Destroyed) for different disaster types (wildfire, landslides, dam collapses, volcanic eruptions, earthquakes/tsunamis, wind, flooding) across over 45,000 km2 of imagery (Gupta et al., 2019). 


\subsection{Case Study Results}

2.3.1 MoM Output: African flooding of June 2020 was used as a case study to test out the model components and their integration in DisasterAWARE® for alerting purpose. Figure 2 shows the flood severity distribution at a sub-watershed level for African countries that were flooded on June $6^{\text {th }}, 2020$. Because alert messages cannot be disseminated to every country within a watershed, and watershed boundaries maintained by WRI are independent of the political boundaries, the countries with high flood severity and present within a watershed were identified for alerting. Figure 3 shows the countries with high flood severity, which were used for alert message generation as well as for flood extent and depth estimation using SAR imagery and impact assessment using optical imagery. The location of the alert points in Figure 3 are the centroids of the countries experiencing flooding shown in Figure 2.

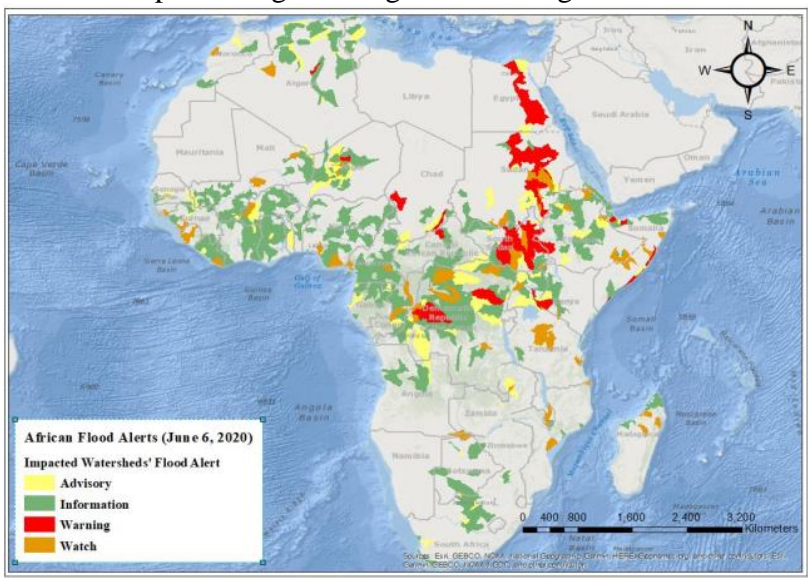

Figure 2. Watershed with flood alert within African Countries on $6^{\text {th }}$ June 2020

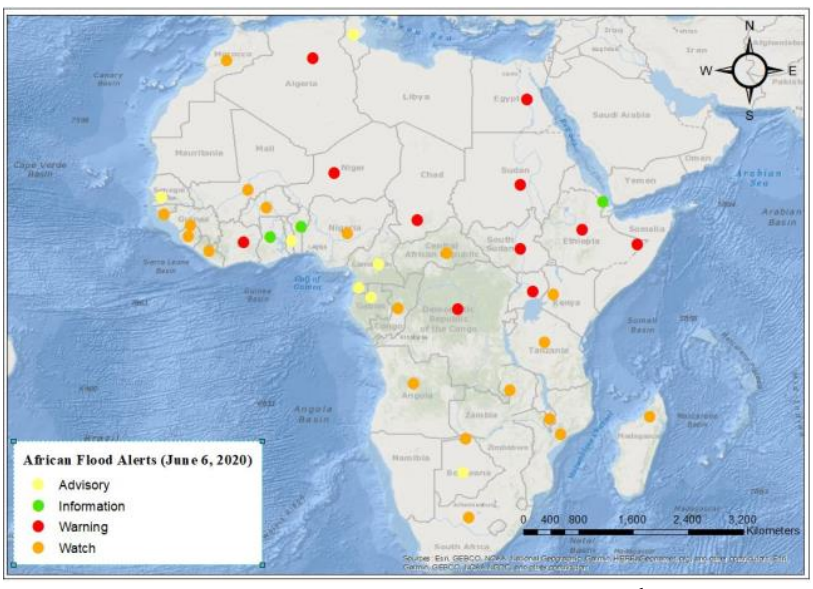

Figure 3. African countries with flood alert on $6^{\text {th }}$ June 2020

2.3.2 SAR output:Figures 4 and 5 show the binary classified image north of Lukolela, the town of the Democratic Republic of the Congo using SAR imagery. The common classifications that allow differentiating between flooded areas vs permanent water bodies are not used in these images. However, a series of outputs comprising water bodies and areas with standing water were created throughout the flood event to determine the flood extent using the change detection approach.

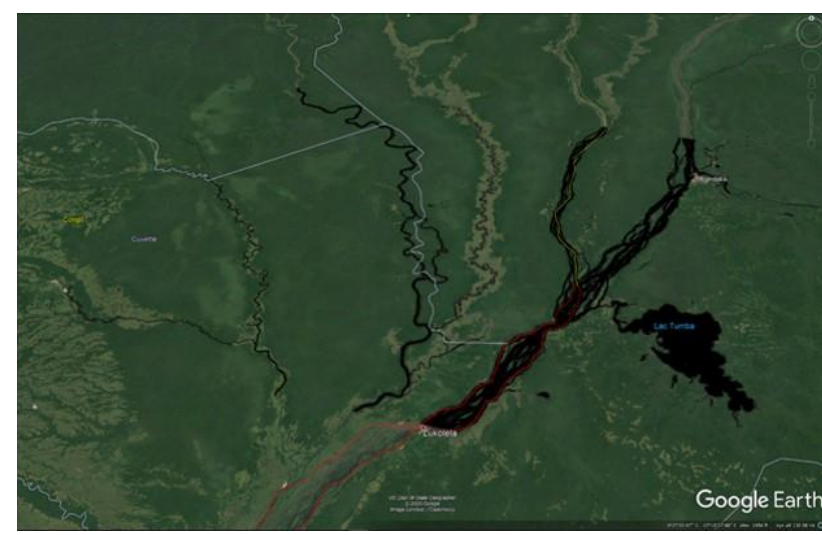

Figure 4: $2020220 \mathrm{VH}$ binary classified image north of Lukolela. Common classifications are not removed in this image.

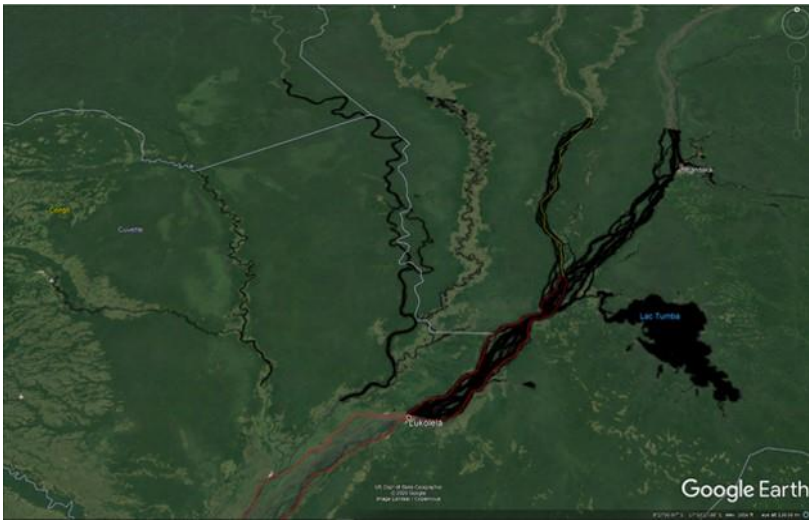

Figure 5: $20200303 \mathrm{VH}$ binary classified image north of Lukolela. Common classifications are not removed in this image.

2.3.3 Infrastructure Impact assessment output: Similar to the xBD data, google earth imagery is a satellite image with atmospheric compensation and thus we used publicly available Google Earth imagery to extract building footprints for Jowhar, Somalia as the case study. This area was impacted by a recent flood in April 2020. Since google earth does not provide ground truth information, we visually inspected the test results and found that the model had missed some small buildings. The reasoning for missing building footprints could be that the Google Earth reference has a low resolution, and it could be improed by using original high-resolution data.

The test performance results of the model using the $\mathrm{xBD}$ datasets are summarized in Table 2. Here we calculated the average precision (AP), the area under the Precision-Recall curve, the mean average precision (mAP) (the average value of AP), recall showing the proportion of the number of correctly allocated positive samples to the total number of positive samples, F1-score, the harmonic mean of precision and recall, and mean intersection-over-union (mIOU) which represents the overlap rate between the generated candidate bound and the ground truth bound. Figure 6 shows the Google Earth imagery and Figure 7 shows the detected building footprints.

\begin{tabular}{cccccc}
\hline & $\begin{array}{c}\text { AP } \\
(\boldsymbol{\%})\end{array}$ & $\begin{array}{c}\text { MAP } \\
(\boldsymbol{\%})\end{array}$ & Recall $(\boldsymbol{\%})$ & $\begin{array}{c}\text { F1- } \\
\text { score }\end{array}$ & $\begin{array}{c}\text { mIoU } \\
(\boldsymbol{\%})\end{array}$ \\
\hline XBD & 96.44 & 87.51 & 75.02 & 0.8439 & 85.52 \\
\hline \multicolumn{5}{c}{ Table 2. Test results of the model on xBD dataset }
\end{tabular}




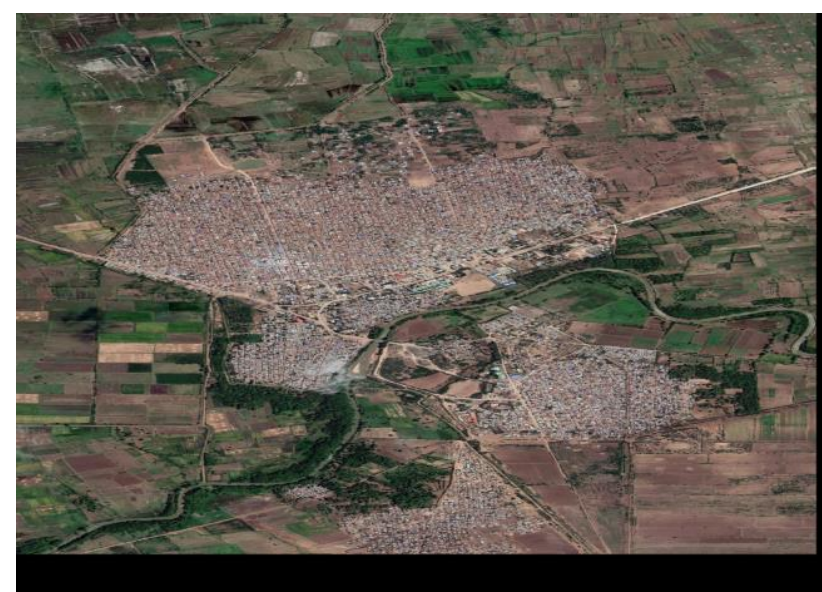

Figure 6. Jowhar original image on April 2020

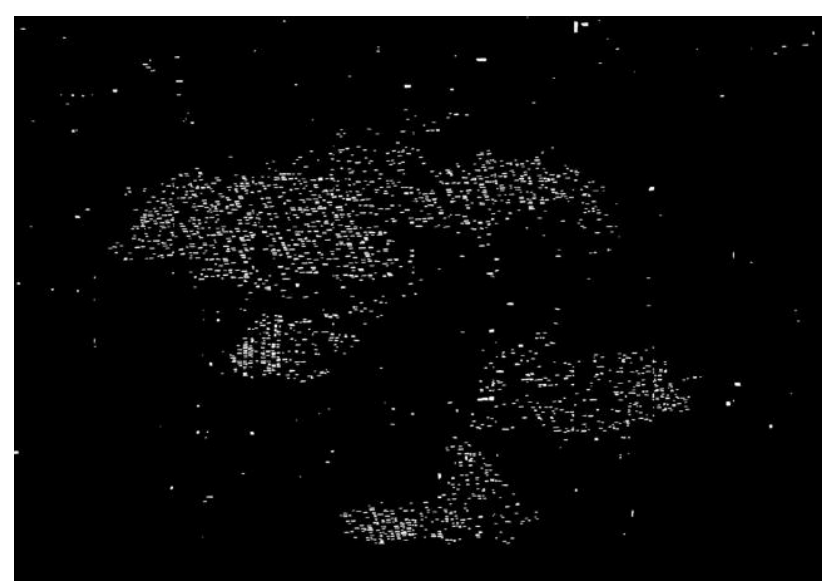

Figure 7. Building footprint detection result in Jowhar

\section{CONCLUSIONS}

The current implementation of the MoM approach generates flood extent output at the watershed level every 6 hours before and during a flood event. The MoM approach integratng outputs from the GloFAS and GFMS models has been automated using Python and Gdal. An equal weighting approach is used to combine the flood model outputs, which can be extended to include other flood model outputs that forecast riverine and coastal flooding, small and large flood events as well as urban flood events.

The MoM output is currently used to identify SAR imagery for high flood severity locations so that flood extent could be generated at a granular level $(15 \mathrm{~m} \times 15 \mathrm{~m}$ resolution) as was the case for African Flood (Figures 4 and 5). The MoM output is also used to obtain optical imagery and geospatial datasets to assess impacts.

The current MoM implementation is part of the DisasterAWARE® system. This integration allows the generation of alerts about potential flood events, their severity and location, and potential impacts on infrastructures to help stakeholders on the ground in partner countries and communities. While such information is useful for resource planning, future expansion of MoM will allow estimation and categorization of damages based on flood severity and depth to help first responders to use the information for response and recovery activities, which is the ultimate focus of this project.

\section{CURRENT LIMITATIONS AND FUTURE DIRECTIONS}

The current version of the MoM approach is undergoing improvements to address the following limitations:

(i) The GFMS is operational on the quasi-global latitude range $\left(50^{\circ} \mathrm{N}-50^{\circ} \mathrm{S}\right)$ and beyond this range MoM output relies on GloFas alone and is likely to miss flooding events;

(ii) Both the GFMS and GloFAS don't foracast storm surge, thus reducing MoM's ability to forecast strom surge events in the coastal areas;

To ensure MoM is comprehensive and precise in forecasting floods and flood impacted areas, future expansion will integrate SAR imagery output along with Digital Elevation Model (DEM) data at a global scale to compute flood depth. Outputs from authoritative sources, such as the Dartmouth Flood Observatory and other models, such as the Rapid Infrastructure flood Tool (RIFT) developed by Pacific Northwest National Laboratry (PNNL) for regional level flood forecasting will also be used to validate the MoM output and increase its usability and accuracy.

While the flood extent is useful in assessing damaged vs not damaged areas and infrastructures, the lack of flood depth information prohibits the impact assessment model from determining damage extent. These future expansion of MoM will increase its use in producing situational awareness information for response and recovery activities.

\section{ACKNOWLEDGEMENTS}

The research was carried out at the Jet Propulsion Laboratory, California Institute of Technology, under a contract with the National Aeronautics and Space Administration (80NM0018D0004).

This manuscript has been authored by UT-Battelle, LLC under Contract No. DE-AC05- 00OR22725 with the U.S. Department of Energy. The U.S. Government retains and the publisher, by accepting the article for publication, acknowledges that the U.S. Government retains a non-exclusive, paid-up, irrevocable, worldwide license to publish or reproduce the published form of this manuscript, or allow others to do so, for United States Government purposes. The findings and opinions presented in this manuscript are those of the authors and do not reflect the policy or position of any of the aforementioned institutions.

\section{REFERENCES}

Alfieri, L., Burek, P., Dutra, E., Krzeminski, B., Muraro, D., Thielen, J., Pappenberger, F., 2013. GloFAS; global ensemble streamflow forecasting and flood early warning. Hydrol. Earth Syst. Sci., 17(3), 1161-1175. doi:10.5194/hess-17-1161-2013

Bing Maps Team., 2018. Microsoft Releases 125 million Building Footprints in the US as Open Data. Last visited $15^{\text {th }}$ July 2020. https://www.microsoft.com/en-us/maps/buildingfootprints

Bruneau, M., Chang, S. E., Eguchi, R. T., Lee, G. C., O'Rourke, T. D., Reinhorn, A. M., Winterfeldt, D. v., 2003. A Framework to Quantitatively Assess and Enhance the Seismic Resilience of Communities. Earthquake Spectra, 19(4), 733752. doi:10.1193/1.1623497 
Cao, H., Zhang, H., Wang, C., Zhang, B., 2019. Operational Flood Detection Using Sentinel-1 SAR Data over Large Areas. Water, 11(4), 786.

CRED., 2020. EM-DAT: The International Disaster Database. Retrieved 2-July 2020, from Université catholique de Louvain https://www.emdat.be/

Cutter, S. L., Barnes, L., Berry, M., Burton, C., Evans, E., Tate, E., Webb, J., 2008. A place-based model for understanding community resilience to natural disasterßct. Global Environmental Change, 18(4), 598-606. doi:https://doi.org/10.1016/j.gloenvcha.2008.07.013

Demirkaya, O., H. Asyali, M., 2004. Determination of image bimodality thresholds for different intensity distributions. Signal Processing: Image Communication, 19(6), 507-516. doi:https://doi.org/10.1016/ j.image.2004.04.002

Donovan, A.; Borie, M., Blackburn, S., 2019. Changing the paradigm for risk communication: Integrating sciences to understand cultures. Contributing Paper to GAR 2019. Available from: https://www.undrr.org/publication/changingparadigm-risk-communication-integrating-sciences-understandcultures

Dutta, D., Herath, S., Musiake, K., 2006. An application of a flood risk analysis system for impact analysis of a flood control plan in a river basin. Hydrological Processes, 20(6), 1365-1384. doi:10.1002/hyp.6092

Earle, P. S., Wald, D. J., Jaiswal, K. S., Allen, T. I., Hearne, M G., Marano, K. D., . . . Fee, J., 2009. Prompt Assessment of Global Earthquakes for Response (PAGER): A System for Rapidly Determining the Impact of Earthquakes Worldwide (2009-1131). Retrieved from http://pubs.er.usgs.gov/publication/ofr20091131

Copernicus Sentinel Data, 2015. Retrieved from ASF DAAC on April, 2020, processed by ESA. https://search.asf.alaska.edu/

Engle, P.L., Castle, S. and P. Menon., 1996. Child Development: Vulnerability and Resilience. Discussion Paper in Food Consumption and Nutrition Division: International Food Policy Research Institute. Available from: http://ebrary.ifpri.org/utils/getfile/collection/p15738coll2/id/125 577/filename/125608.pdf.

Emerton, R. E., Stephens, E. M., Pappenberger, F., Pagano, T. C., Weerts, A. H., Wood, A. W., Cloke, H. L., 2016. Continental and global scale flood forecasting systems. WIREs Water, 3(3), 391-418. doi:10.1002/wat2.1137

Etten, A. V., Lindenbaum, D., \& Bacastow, T. M., 2019. SpaceNet: A Remote Sensing Dataset and Challenge Series. arXiv(Computer Vision and Pattern Recognition (cs.CV)). doi:arXiv:1807.01232v3

Federal Emergency Management Agency., 2012. Integrated alert and warning system (IPAWS). http://www.fema.gov/emergency/ipaws/index.shtm

Gladwin, H., Lazo, J. K., Morrow, B. H., Peacock, W. G., Willoughby, H. E., 2007. Social science research needs for the hurricane forecast and warning system. Natural Hazards Review, 8(3), 87 - 95

Gupta, R., Hosfelt, R., Sajeev, S., Patel, N., Goodman, B. Doshi, J., Gaston, M., 2019. xBD: A Dataset for Assessing Building Damage from Satellite Imagery. $\quad c s . C V$. doi:arXiv:1911.09296

He, K., Gkioxari, G., Dollár, P., Girshick, R., 2017. Mask R-CNN. 2017 IEEE International Conference on

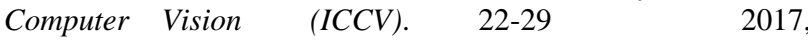
Venice, Italy., http://iccv2017.thecvf.com

Hofste, R. W., Kuzma, S., Walker, S., Sutanudjaja, E. H., Bierkens, M. F. P., kuijper, M. J. M., Reig, P., 2019. Aqueduct 3.0: Updated Decision-Relevant Global Water Risk Indicators. Retrieved from Washinton, DC: avilable online at: https://www.wri.org/publication/aqueduct-30.

Holling, C. S., 1973. Resilience and Stability of Ecological Systems. Annual Review of Ecology and Systematics, 4(1), 1-23. doi:10.1146/annurev.es.04.110173.000245

Jain, S. K., Mani, P., Jain, S. K., Prakash, P., Singh, V. P., Tullos, D., Dimri, A. P., 2018. A Brief review of flood forecasting techniques and their applications. International Journal of River Basin Management, 16(3), 329-344. doi:10.1080/15715124.2017.1411920

Kar, B., Bausch, D., Wang, J., Sharma, P., Chen, Z., Schumann, G., Pierce, M., Tiampo, K., Eguchi, R., Glasscoe, M., 2020. An Integrated Model of Models for Global Flood Alerting. $7^{\text {th }}$ International Conference on Flood and Urban Water Management, $\quad$ September 2020, Online https://www.wessex.ac.uk/conferences/2020/friar-2020

Klein, R.J.T., Nicholls, R.J., Thomalla, F., 2003. The Resilience of Coastal Megacities to weather-related hazards. In Kreimer, A., Arnold, M., Carlin, A. (eds)., Building safer cities: The future of disaster risk. Washington D.C.: The World Bank Disaster Management Facility.

Krimsky, S., 2007. Risk communication in the internet age: The rise of disorganized skepticism. Environmental Hazards, 7, 157 -164 .

McCubbin, L., 2001. Challenges to the Definition of Resilience. Paper presented at the Annual Meeting of the American Psychological Association, San Francisco, CA.

Mileti, D.S., 1999. Disasters by Design: a Reassessment of Natural Hazards in the United States. Joseph Henry Press, Washington, DC

Olesen, L., Löwe, R., Arnbjerg-Nielsen, K., 2017. Flood damage assessment - Literature review and recommended procedure. Cooperative Research Centre for https://watersensitivecities.org.au/content/flood-damage-bourne, assessment-literature-review-recommended-procedure/

Palen, L., Vieweg, S., Liu, S. B., \& Hughes, A. L., 2009. Crisis in a networked world features of computermediated communication in the April 16, 2007, Virginia Tech event. Social Science Computer Review, 27(4), 1-14 
Paton, D., Johnston, D., 2006. Disaster Resilience: An Integrated Approach. Charles C. Thomas, Springfield, IL.

Renschler, C., Frazier, A., Arendt, L., Cimellaro, G., Reinhorn, A., Bruneau, M., 2010. Framework for defining and measuring resilience at the community scale: The PEOPLES resilience framework (MCEER-10-0006). University of Buffalo, Buffalo, NY, http://www.eng.buffalo.edu/mceer-reports/10/10-0006.pdf

Reynolds, B., \& Seeger, M. W., 2005. Crisis and emergency risk communication as an integrative model. Journal of Health Communication, 10, 43-55.

Rose, A., 2004. Defining and Measuring Economic Resilience to Disasters. Disaster Prevention and Management, 13 (4): 307 314.

Tinch, R., 1998. Resilience and Resource Management Under Risk, School of Environmental Science, University of East Anglia, Norwich

UNDRR, 2015. Sendai Framework for Disaster Risk Reduction 2015-2030, United Nations. https://www.preventionweb.net/files/43291_sendaiframeworkfo rdrren.pdf.

United Nations University, 2004. Two Billion Vulnerable To Floods By 2050; Number Expected To Double Or More In Two Generations. Science Daily. Retrieved from www.sciencedaily.com/releases/2004/06/040614081820.htm

UN/ISDR (Inter-Agency Secretariat of the International Strategy for Disaster Reduction), 2005. Hyogo framework for action 2005-2015: Building the resilience of nations and communities to disasters (HFA). Kobe, Japan: UNISDR.

Viner, D., Ekstrom, M., Hulbert, M., Warner, N. K., Wreford, A., Zommers, Z., 2020. Understanding the dynamic nature of risk in climate change assessments-A new starting point for discussion. Atmospheric Science Letters, 21(4), e958. doi:10.1002/as1.958

Winsemius, H. C., Van Beek, L. P. H., Jongman, B., Ward, P. J., Bouwman, A., 2013. A framework for global river flood risk assessments. Hydrol. Earth Syst. Sci., 17(5), 1871-1892. doi:10.5194/hess-17-1871-2013

Wu, H., Adler, R. F., Tian, Y., Huffman, G. J., Li, H., Wang, J., 2014. Real-time global flood estimation using satellite-based precipitation and a coupled land surface and routing model. Water Resources Research, 50(3), 2693-2717. doi:10.1002/2013wr014710 